in those infants who were discharged apparently normal and free of sequelae. ${ }^{1 / 1 \times}$

These factors added together make it extremely important that an accurate neonatal history is available when such infants come to hospital. The memory of the accompanying parent may be unreliable. If the infant has originally been transferred from local facilities to a neonatal regional centre the paediatric medical and surgical staff may not always have instant access to neonatal records. Changes of name may confuse the search for previous records $\left(10^{\circ}\right.$ of this group had a different surname by the end of one year), and many admissions result from self referral so that the general practitioner's information is not available. Each area requires its own contingency plans for obtaining data in these situations, certainly within 24 hours of admission if not immediately.

This population of infants provides "new" problems for anaesthetists, paediatricians, and paediatric surgeons in addition to their better known and multiple neurodevelopmental difficulties. They also require proportionately more (here 16.4 times more) facilities for inpatients than term infants.

Even those infants who had apparently uncomplicated neonatal courses appeared to have considerably raised incidences of morbidity and even mortality throughout infancy, suggesting adverse consequences or correlates of their low birth weight itself. As being in hospital itself can lead to deleterious consequences in development at 2 years, ${ }^{19}$ and in later behaviour and learning even in adolescence, ${ }^{20}$ the importance of these medical and surgical problems should not be underestimated.

I thank Dr E J Bushby, Dr R W I Cooke, and the consultants o Alder Hey Children's Hospital and the Royal Liverpool Children's Hospital for allowing me access to their patients' records.

\section{References}

1 Hurt H. Continuing care of the high-risk infant. Clin Perinatol 1984;11:3-17 Hurt H. Continuing care of the high-risk infant. Clin Perinatol 1984;11:3-17
McCormick MC, Shapiro S, Stanfield BH. Rehospitalization in the first year of life for high-risk survivors. Pediatrics 1980;66:991-9.

Hack M, DeMonterice D, Merkatz IR, Jones P, Fanaroff AA. Rehospitalization of the very low birth weight infant: a continuum of perinatal and environmental morbidity. Am 7 Dis Child $1981 ; 135 \cdot 263-6$

4 Markestad T, Fitzhardinge PM. Growth and development in children recovering from broncho-pulmonary dysplasia. F Pediatr 1981;98:597-602.

Littman B, Parmelee AH. Medical correlates of infant development. Pediatric $1978 ; 61: 470-4$

6 Pape KE, Buncic RJ, Ashby S, Fitzhardinge PM. The status at two years of low birth weight infants born in 1974 with birth weights of less than 1001 grams. f Pediatr 1978;92:253-60

7 Fitzhardinge PM, Pape K, Arstikaitis M, ct al. Mechanical ventilation of infants of less than 1501 grams birth weight: health, growth and neurologic sequelac

Cullinan TR, Saunders DI. Prediction of infant hospital admission risk. Arch Dis

ynne J, Hull D. Why are children admitted to hospital? Br Med f 1977; ii:

10 Taylor B, Wadsworth J, Butle NR. Teenage mothering, admission to hospital, and accidents during the first five years. Arch Dis Child 1983;58:6-11.

11 Outerbridge EW, Nogrady MB, Beaudry PH, Stern L. Idiopathic respiratory distress syndrome. Recurrent respiratory illness in survivors. Am $\mathcal{F}$ Dis Child 1972;123:99-104.

12 Lindroth $M$, Johnson B, Svenningsen NW, Mortensson WW. Pulmonary mechanics, chest $\mathrm{X}$ ray, and lung disease after mechanical veintilation in low birth weight infants. Acta Paediatr Scand 1980;69:761-70

13 Stocks J, Godfrey S. Role of artificial ventilation, oxygen, and CPAP in the pathogenesis of lung damage in neonates: assessment by serial measurements of lung function. Pediatrics 1976;57:352-62.

14 Chamberlain RN, Simpson RN. The prevalence of illness in childhood. London:

15 Carmichael A, W'illiams HE. Patterns of illness in an infant population in a poor socio-economic status multi-ethnic municipality. Aust Paediatr $71983 ; 19$ :

16 Lloyd B, Pursall E, Emery JL. Hospital morbidity pattern in children under 1 year of age born in Sheffield 1975-6. Arch Dis Child 1981;56:36-9.

17 Kulkarni P, Hall RT, Rhodes PG, Sheehan MB. Postneonatal infant mortality in infants admitted to a neonatal intensive care unit. Pediatrics $1978 ; 62: 178-83$. Sells CJ, Neff TE, Bennett I:C, Robinson NM. Mortality in infants discharged from a neonatal intensive care unit. Am f Dis Child 1983;137:44-7.

9 Littman B, Parmelee AH. Medical correlates of infant development. Pediatric $1978 ; 61: 470-4$

20 Douglas JWP. Early hospital admissions and later disturbances of behaviour and learning. Dev Med Child Neurol 1975;17:456-80.

(Accopted 4 fune 1985)

\title{
Treatment of ingrowing toenails with liquid nitrogen spray cryotherapy
}

\author{
T S SONNEX, R P R DAWBER
}

\begin{abstract}
Ingrowing toenails are a common debilitating condition and often require surgical intervention. In 44 patients liquid nitrogen spray cryotherapy produced a rate of success comparable with that of other nail sparing techniques but had the advantage of being a quick, simple, and cheap outpatient procedure that could be carried out with limited facilities and without anaesthesia.
\end{abstract}

\section{Introduction}

Ingrowing toenails are common, particularly in young adults, and usually result in a prolonged period of discomfort or pain

Department of Dermatology, Slade Hospital, Oxford OX3 7JH

T S SONNEX, MB, MRCP, registrar

R P R DAWBER, MB, FRCP, consultant

Correspondence to: Dr T S Sonnex, St John's Hospital for Diseases of the Skin, London WC2H 7BJ. that is sufficient to interfere with working and social activities. Several aetiological factors have been implicated, including ill fitting footwear, incorrect cutting of nails, poor foot hygiene, hyperhidrosis, malalignment of the matrix, abnormally long toes, congenital excessive convexity of the nails, and prominence of the nail folds. Although a fundamental aim of management must be to correct these predisposing factors, further measures are usually required at the time of presentation. Antiseptic soaks, systemic antibiotics, regular pushing back of the nail fold, and packing of the lateral groove with cotton wool are usually tried, but a response, if it occurs, takes time and considerable effort by the patient. As recurrences are common an operation is the next inevitable step.

Nail ablation consistently produces the highest cure rates but is relatively time consuming and requires a high degree of skill by the operator. Patients are also not keen to lose part of the nail permanently unless there is no alternative. Any feasible alternative should be a simple, quick, cheap outpatient procedure that can be carried out with limited facilities by relatively inexperienced operators and that produces rapid relief of pain associated with an acceptable cure rate.

As cryotherapy fits most of these criteria we considered its use in the treatment of ingrowing toenails. Four of the main features of ingrowing toenails are pain, secondary infection, excessive 
granulation tissue, and prominent nail folds. Cryotherapy produces fully reversible functional changes in peripheral nerves, ${ }^{1}$ and it is thought to be through this mechanism that lesions treated by cryotherapy are subsequently free of pain. Liquid nitrogen also eradicates infection and is especially effective in destroying granulation tissue, as shown by the successful treatment of pyogenic granuloma." Theoretically, therefore, we would expect a beneficial response after treatment with cryotherapy. We carried out this study to investigate the degree of benefit.

\section{Patients and methods}

Forty four consecutive patients referred with ingrowing toenails were treated by cryotherapy. All patients had painful lesions (bilateral in four) with secondary infection and abundant granulation tissue. Ingrowing toenails in 11 patients had recurred after avulsion of the nail, and eight patients had been unsuccessfully treated by resection of the lateral nail and matrix. The duration of the lesions before referral ranged from eight to 29 months (mean 22 months). The aetiological factors found in our patients were ill fitting footwear, incorrect cutting of nails, and prominent nail folds. None had malalignment of the matrix ${ }^{3}$ hyperhidrosis, or abnormally long toes.

Aspirin $600 \mathrm{mg}$ was given before treatment, and none of the patients subsequently required local anaesthesia. A CryOwen liquid nitrogen spray gun fitted with an intermediate sized (B) nozzle, held $1 \mathrm{~cm}$ from the target area, was used to treat all patients. By this method freezing was produced in a well defined area and protection of surrounding tissue was not necessary, particularly as we did not need to encroach on to the matrix of the nail in any patient. The freeze time was for 30 seconds after the treatment (ice) field had been established. The area treated included all the granulomatous and infected areas as well as the adjacent nail fold. This freeze time was chosen because previous studies had shown that this was adequate to destroy granulation tissue and eradicate infection yet was unlikely to induce scarring ${ }^{4}$; it also cures many benign vascular tumours of the skin.

To minimise inflammation after treatment each patient continued to take aspirin $600 \mathrm{mg}$ four to six hourly for 48 hours and applied a potent combined steroid antibiotic cream (Dermovate-NN, Glaxo Laboratories) six hourly under a dry dressing until exudation of serous fluid occurred, usually after about 18 hours. During this exudative phase the treated area was soaked daily for 20 minutes in $1 / 10000$ solution of potassium permanganate before a non-adhesive dressing was reapplied. Within four to five days the lesions had dried, leaving a crusted wound requiring only simple dry dressings during activity. Within one to two weeks these dressings were abandoned by most patients.

All patients were treated in our outpatient consulting rooms, each procedure taking only 15 minutes, including dressing. Systemic antibiotics were not used, and patients were instructed how to apply their dressings at home. General advice was given to the patients aimed at correcting the aetiological factors, but no further specific measures were taken.

\section{Results}

In 24: patients complete resolution occurred with no signs of recurrence during 13-18 months' follow up. Of these 24 patients, seven had been previously treated unsuccessfully by surgical procedures including avulsion of the nail (with or without curettage and phenolisation) and removal of the lateral nail and matrix. The remaining 20 patients responded initially with loss of infection and granulation tissue, but recurrence developed within one to three months. Six patients were retreated using exactly the same technique, complete resolution occurring in four, who remained free from recurrence during 14 months' follow up. In the remaining two the nails cleared initially but granulation tissue redeveloped within one to two months. If these six retreated patients are added to those whose ingrowing toenails did not recur after a single treatment the overall rate of success was $63.6 \%$ (28 patients).

Noticeable relief of pain occurred within one to two days in all patients and lasted for three to 15 months, even in those patients in whom infection and granulation tissue had recurred. This facilitated an early return to work and social activities. The treated nail folds were unchanged macroscopically with no scarring or loss of bulk.

Morbidity was not a problem; aspirin was sufficient to control discomfort after cryotherapy and was not required by any patient for $\square$ longer than 48 hours. All patients were able to cope satisfactorily with their dressings at home without medical help. Subsequently, $\frac{3}{8}$ five patients developed patchy leuconychia and four developed painless $\varrho$ onycholysis. These resolved within two to three months.

\section{Discussion}

Although conservative management may provide cure or at least acceptable control, many patients need more radical treatment for their ingrowing toenail. Surgical procedures can be $\Rightarrow$ divided into two broad groups depending on whether permanent $\stackrel{\text { S }}{\rightarrow}$ loss of part or all of the nail plate results.

Avulsion of the nail plate is probably the most commonly used nail sparing procedure despite reported recurrences of $\frac{\omega}{5}$ $67 \% \%^{5}$ and $64 \%{ }^{6}$ for first avulsions, with $86 \%$ after second ${ }^{\Phi}$ avulsions and $80 \%$ after more than two avulsions. Murray and Bedi thought that this procedure should be a primary surgical $\rightarrow$ procedure as it possessed the advantages of eradicating infection. and relieving symptoms rapidly. ${ }^{6}$ Partial avulsion of nails is $\vec{\omega}$ also popular: Cameron reported that $61 \%$ of patients were cured $\mathscr{N}$ at six months. ${ }^{7}$ The patients selected, however, had experienced $\frac{\sigma}{3}$ symptoms for only one month or less and had only mild infection and no permanent deformity of the nail fold. Even so they $\stackrel{C}{-}$ were advised after the operation to abstain from physical educa- $\sigma$ tion and field sports for one month and to dry pack the nail fold $\underset{\infty}{+}$ for a further three months.

An alternative approach is to reduce the bulk of the nail fold $\vec{\omega}$ and its proximity to the nail by resection of soft tissue. Murray 0 and Robb reported that $60 \%$ of patients were cured after nine months using this method, although in $80 \%$ of cases preliminary $\mathrm{N}$ avulsion of the nail was required (two to three weeks before $\subseteq$ resection of soft tissue) to reduce the degree of sepsis present. ${ }^{8<}$ Wallace $e t$ al used a polyethylene gutter that was inserted along $\vec{\varphi}$ the lateral edge of the nail after prior excision of all granulation or tissue and left in place for eight to 12 weeks. ${ }^{5}$ A success rate of $\square$ $56 \%$ (with a one year follow up) was reported for selected patients with an ingrowing toenail of recent onset, no abnormal thickening of the nail, and no history of operations.

Nail reducing techniques have higher rates of success but $\frac{\circ}{\circ}$ because of the need for greater skill by the operators and time they tend to be reserved for those patients who are not respond- $\overrightarrow{\overrightarrow{0}}$ ing to conservative or nail sparing methods. By performing segmental excision of the germinal matrix (wedge resection) Wallace $e t$ al cured $84 \%$ of patients, ${ }^{5}$ while Townsend and Scott, using Zadik's total proximal nail bed ablation, ${ }^{9}$ reported satisfactory results in $89 \%$ of cases. ${ }^{10}$ Partial or total phenolisation (phenol cauterisation) of the nail bed with a reported recurrence $\frac{0}{3}$ of $4 \%$ over nine months' follow up ${ }^{11}$ is superseding surgical $\frac{3}{9}$ ablation techniques because of the advantages that it can be performed in the presence of sepsis, is less painful during and after operation, is easier to perform, and produces better cos- $\frac{\text { o }}{2}$ metic results.

Our results with cryotherapy confirm the susceptibility of infection and granulation tissue to low temperature. Rapid relief $\frac{7}{0}$ of pain was a noticeable finding and correlates with the general observation that areas treated by cryotherapy are subsequently relatively free from pain. The mechanism is thought to be $\omega$ functional changes induced in peripheral nerves by the cold. ${ }^{1}$ 年 An additional advantage is that lesions can be retreated two toce three months later without discomfort.

The lack of effect on the lateral nail fold was not surprising $\stackrel{?}{?}$ as the freeze time used in this study would not be expected to cause damage to the framework of connective tissue. ${ }^{4}$ It may be $\frac{\text { Tे }}{\mathbb{D}}$

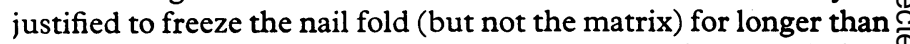
30 seconds to produce damage to connective tissue and thus $\mathbb{D}$ obtain a reduction in bulk of the lateral nail fold with retraction? of the soft tissue away from the nail. The fact that over $60 \%$ of $ᄋ$ our patients were cured despite our not having first removed anyo nail spicules might imply that we were producing a degree of retraction of the nail fold that was not detected clinically.

Townsend and Scott reported that after operations $89 \%$ of 
recurrences developed within one year, most within six months. ${ }^{10}$ Thus our success rate of $64 \%$ after 13-18 months' follow up probably reflects the long term cure rate for cryotherapy in an unselected group of patients with ingrowing toenails. This success rate might be increased if cryotherapy was combined with a method of reducing the bulk of the nail fold, either by resection of soft tissue or by an increased freeze time.

Although nail reducing techniques are the most successful, patients may not be willing to lose permanently part or all of their toenail if a nail sparing technique would succeed. Even the most basic of these techniques, however, requires an anaesthetic, skill of the operator, suitable operating facilities, and time. Cryotherapy, however, is a quick, simple, and cheap nail sparing procedure that can be carried out without anaesthesia with limited facilities, has a rate of success comparable with that of surgical nail sparing procedures, and produces rapid relief of pain in most cases.

\section{References} 1 Barnard JDW, Lloyd JW, Glynn CJ. Cryosurgery in the management of in-

Zacharian SA. Cryosurgery of tumors of the skin and oral cavity. 1st ed. Springfield Illinois: Charles $\mathrm{C}$ Thomas, 1973 .

3 Baran R, Bureau H. Congenital malalignment of the big toe-nail as a cause of ingrowing toe-nail in infancy. Pathology and treatment (a study of thirty cases). Clin Exp Dermatol 1983;8:619-23.

4 Shepherd J. Effects of freezing on various dermal connective tissue components. Oxford: University of Oxford, 1979. (MSc thesis.)

Wallace WA, Milne DD, Andrew T. Gutter treatment for ingrowing toe nails.

Murray WR, Bedi BS. The surgical management of ingrowing toe nails. $\mathrm{Br} \mathcal{J}$ Surg $1975 ; 62: 409-12$

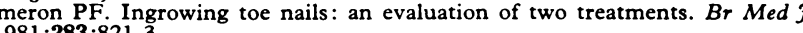
$1981 ; 283: 821-3$

urray W R Surg Oncol 1981;7:157-8.

Zadik FR. Obliteration of the nail-bed of the great toe without shortening the terminal phalanx. F Bone foint Surg 1950;32:66-7.

10 Townsend AC, Scott PJ. Ingrowing toe nail and onychogryposis. $\mathcal{f}$ Bone foint Surg 1966;48:354-8.

11 Robb JE, Murray WR. Phenol cauterisation in the management of ingrowing toe nails. Scott Med $\dot{f} 1982 ; 27: 236-9$.

(Accepted 20 March 1985)

\section{Effect of a regional neonatal unit on a general paediatric ward}

Increasing numbers of infants are surviving as a result of specialised care in neonatal intensive care units. Some require readmission to hospital, ${ }^{12}$ either for further treatment of neonatal complications such as posthaemorrhagic hydrocephalus or for recurrent respiratory infections and apnoeic episodes due to the development of chronic lung disease after ventilation. Failure to thrive and child abuse are more common in these infants. ${ }^{3}$ Many require prolonged inpatient medical care, and in this study we investigated the proportion of the workload of a paediatric ward that was generated by infants who had previously been treated in a neonatal intensive care unit.

\section{Methods}

All patients admitted to the regional neonatal intensive care unit at Cambridge Maternity Hospital during 1982 were studied and divided according to whether they were born inside or outside the Cambridge Health Authority area. Records of infants admitted to the paediatric ward in the same hospital were analysed. The ward admitted children under 5 years except those re- quiring ear, nose, and throat surgery or plastic surgery. The only regional commitment was for neurosurgical cases. Acute admissions were from the Cambridge area, although babies from outside this area who had previously been in the neonatal intensive care unit were readmitted on request. Diagnosis and length of stay of patients under 1 year old in the paediatric ward during 1982 were analysed. All admissions to the paediatric ward during 1982-3 of infants who had previously been in the intensive care unit during their first year were also recorded. Using this data, a comparison was made between those infants (under 1 year old) who had previously had treatment in the neonatal intensive care ward and those who had not.

\section{Results}

In 1982,439 children under 1 year were admitted to the paediatric ward with a bed occupancy of 3386 days. Of 402 infants admitted to the neonata intensive care unit, 133 were from the Cambridge area and 14 were subsequently admitted to the paediatric ward, before their first birthday, for a tota of 193 days. Of the 269 infants from the region who had previously been in the intensive care unit, 38 were admitted to the paediatric ward during their firs year of life for a total of 1222 days. They thus accounted for $42 \%$ of the bed occupancy of the under 1 year olds. Seventy seven infants with birth weights under $1500 \mathrm{~g}$ were admitted to the neonatal intensive care unit. Nine of the 16 from the Cambridge area who survived required admission to the general ward for a total of 200 days, and eight of the region's 37 surviving infants for 206 days. Thus 17 out of 53 survivors $(32 \%$ ) (birth weight $<1500$ g) were

Diagnoses in children aged under 1 year admitted to hospital

\begin{tabular}{|c|c|c|c|c|c|c|}
\hline & \multicolumn{3}{|c|}{ Infants who had been in neonatal intensive care unit } & \multicolumn{3}{|c|}{ Other infants } \\
\hline & $\mathbf{n}$ & $\begin{array}{l}\text { No of days } \\
\text { admitted }\end{array}$ & Mean No of days & $\mathbf{n}$ & $\begin{array}{l}\text { No of days } \\
\text { admitted }\end{array}$ & Mean No of days \\
\hline Gastrointestinal surgery & 4 & 590 & $147 \cdot 5$ & 19 & 109 & $5 \cdot 7$ \\
\hline $\begin{array}{l}\text { Chronic lung disease } \\
\text { Neurosurgery }\end{array}$ & $\begin{array}{l}2 \\
7\end{array}$ & $\begin{array}{l}202 \\
214\end{array}$ & $\begin{array}{l}101 \\
30 \cdot 6\end{array}$ & 23 & 299 & 13 \\
\hline Upper respiratory tract infection & 15 & 156 & $10 \cdot 4$ & 59 & 186 & $3 \cdot 2$ \\
\hline Whooping cough & 2 & 47 & $23 \cdot 5$ & 11 & 132 & 12 \\
\hline Feeding problems & $\begin{array}{l}3 \\
1\end{array}$ & $\begin{array}{l}46 \\
28\end{array}$ & $\begin{array}{l}15 \cdot 3 \\
28\end{array}$ & 17 & 79 & $4 \cdot 6$ \\
\hline $\begin{array}{l}\text { Meningitis } \\
\text { Social }\end{array}$ & 2 & 23 & $28 \cdot 5$ & $\begin{array}{r}10 \\
7\end{array}$ & $\begin{array}{l}92 \\
39\end{array}$ & $\begin{array}{l}9 \cdot 2 \\
5 \cdot 6\end{array}$ \\
\hline Developmental delay & 2 & 21 & 10.5 & 7 & 42 & $\begin{array}{l}30 \\
6\end{array}$ \\
\hline Bronchitis & 2 & 11 & $5 \cdot 5$ & 43 & 193 & $4 \cdot 5$ \\
\hline Apnoea & 5 & 17 & $\begin{array}{l}3.4 \\
4.5\end{array}$ & 19 & 89 & $4 \cdot 7$ \\
\hline $\begin{array}{l}\text { Hernia } \\
\text { "Asthma" }\end{array}$ & $\begin{array}{l}2 \\
2\end{array}$ & $\begin{array}{l}9 \\
9\end{array}$ & $\begin{array}{l}4 \cdot 5 \\
4 \cdot 5\end{array}$ & 7 & 18 & $2 \cdot 6$ \\
\hline $\begin{array}{l}\text { "Asthma" } \\
\text { Febrile convulsion }\end{array}$ & 3 & 13 & $4 \cdot 3$ & $\begin{array}{r}6 \\
11\end{array}$ & $\begin{array}{l}15 \\
32\end{array}$ & $\begin{array}{l}2.5 \\
2.9\end{array}$ \\
\hline Jaundice & 2 & 8 & 4 & 4 & 27 & $6 \cdot 8$ \\
\hline Diarrhoea and vomiting & 1 & 7 & 7 & 38 & 102 & $2 \cdot 7$ \\
\hline Pyloric stenosis & 2 & 10 & 5 & 15 & 81 & $5 \cdot 4$ \\
\hline $\begin{array}{l}\text { Tachycardia } \\
\text { Convulsions }\end{array}$ & 1 & 4 & 4 & $\begin{array}{r}1 \\
17\end{array}$ & $\begin{array}{r}4 \\
71\end{array}$ & $\begin{array}{l}4 \\
4 \cdot 2\end{array}$ \\
\hline Computed tomography & & & & 12 & 16 & $1 \cdot 3$ \\
\hline $\begin{array}{l}\text { Pyrexia of undetermined origin } \\
\text { Failure to thrive }\end{array}$ & & & & 21 & 55 & $2 \cdot 6$ \\
\hline $\begin{array}{l}\text { Fanure to thrive } \\
\text { Bronchiolitis }\end{array}$ & & & & $\begin{array}{r}21 \\
9\end{array}$ & 35 & $\begin{array}{l}4.4 \\
3.9\end{array}$ \\
\hline Osteomyelitis & & & & 2 & 12 & 6 \\
\hline Stridor & & & & 2 & 67 & $33 \cdot 5$ \\
\hline $\begin{array}{l}\text { Non-accidental injury } \\
\text { Poisoning }\end{array}$ & & & & $\begin{array}{l}2 \\
1\end{array}$ & $\begin{array}{r}60 \\
2\end{array}$ & $\begin{array}{r}30 \\
2\end{array}$ \\
\hline Cardiac & & & & 3 & 19 & $6 \cdot 3$ \\
\hline Haematological & & & & 1 & 3 & 3 \\
\hline
\end{tabular}

